\title{
Classification of personal exposure to radio frequency electromagnetic fields (RF-EMF) for epidemiological research: evaluation of different exposure assessment methods
}

Patrizia Frei, ${ }^{\mathrm{a}, \mathrm{b}}$ Evelyn Mohler, ${ }^{\mathrm{a}, \mathrm{b}}$ Alfred Bürgi, ${ }^{\mathrm{c}}$ Jürg Fröhlich, ${ }^{\mathrm{d}}$ Georg Neubauer, ${ }^{\mathrm{e}}$ Charlotte Braun-Fahrländer,a, Martin Rööslia, and the QUALIFEX-team

${ }^{a}$ Swiss Tropical and Public Health Institute, Switzerland

${ }^{b}$ University of Basel, Switzerland

'ARIAS umwelt.forschung.beratung, Bern, Switzerland

${ }^{d}$ Laboratory for Electromagnetic Fields and Microwave Electronics, ETH Zurich,

Switzerland

${ }^{\circ}$ EMC \& Optics, Seibersdorf Labor, Austria

Corresponding Author:

Martin Röösli

Swiss Tropical and Public Health Institute

Socinstrasse 57

CH-4002 Basel

Phone: +41 (0)612702215

Fax: +41 (0)6127022 25

mailto: martin.roosli@unibas.ch 


\section{Abstract}

The use of personal exposure meters (exposimeters) has been recommended for measuring personal exposure to radio frequency electromagnetic fields (RF-EMF) from environmental far-field sources in everyday life. However, it is unclear to what extent exposimeter readings are affected by measurements taken when personal mobile and cordless phones are used. In addition, the use of exposimeters in large epidemiological studies is limited due to high costs and large effort for study participants. In the current analysis we aimed to investigate the impact of personal phone use on exposimeter readings and to evaluate different exposure assessment methods potentially useful in epidemiological studies. We collected personal exposimeter measurements during one week and diary data from 166 study participants. Moreover, we collected spot measurements in the participants' bedrooms and data on selfestimated exposure, assessed residential exposure to fixed site transmitters by calculating the geo-coded distance and mean RF-EMF from a geospatial propagation model, and developed an exposure prediction model based on the propagation model and exposure relevant behavior. Mean personal exposure was $0.13 \mathrm{~mW} / \mathrm{m}^{2}$, when measurements during personal phone calls were excluded and $0.15 \mathrm{~mW} / \mathrm{m}^{2}$, when such measurements were included. The Spearman correlation with personal exposure (without personal phone calls) was 0.42 (95\%CI: 0.29 to 0.55$)$ for the spot measurements, -0.03 (95\%-CI: -0.18 to 0.12$)$ for the geo-coded distance, 0.28 (95\%-CI: 0.14 to 0.42$)$ for the geospatial propagation model, 0.50 (95\%-CI: 0.37 to 0.61 ) for the full exposure prediction model and 0.06 (95\%-CI: -0.10 to 0.21 ) for selfestimated exposure. In conclusion, personal exposure measured with exposimeters correlated best with the full exposure prediction model and spot measurements. Self-estimated exposure and geo-coded distance turned out to be poor surrogates for personal exposure. 
Key words: Radio frequency electromagnetic field (RF-EMF); exposure assessment method; mobile phone base station; Wireless LAN (W-LAN); DECT cordless phone; radio and television broadcast 


\section{Introduction}

Exposure to radio frequency electromagnetic fields (RF-EMF) in everyday life is highly temporally and spatially variable due to various emitting sources like broadcast transmitters or wireless local area networks (W-LAN). The use of personal exposure meters (exposimeters) has been recommended in order to characterize personal exposure to RFEMFs (Neubauer et al., 2007). Several exposure assessment studies have been conducted so far using exposimeters, (Joseph et al., 2008; Kühnlein et al., 2009; Thomas et al., 2008; Thuróczy et al., 2008; Viel et al., 2009), which allow capture of exposure from all relevant RF-EMF sources in the different environments where a study participant spends time (Neubauer et al., 2007; Radon et al., 2006). They are suitable for measuring RF-EMF from environmental far-field sources like mobile phone base stations, but are less apt to accurately measure exposure to personal mobile or cordless phones (Inyang et al., 2008) because measurements during personal phone calls are dependent on the distance between the emitting device and the exposimeter. It is therefore expected that mean values obtained with exposimeter measurements are influenced by the personal phone use of the study participants, which is not desirable when using exposimeters for measuring environmental RF-EMF exposure. However, the extent to which exposimeter measurements are affected by RF-EMF sources close to the body is unknown. Other methods have been proposed for estimating RFEMF exposure from sources operating close to the body, such as self-reported use of cordless and mobile phones or operator data (Vrijheid et al., 2009).

The use of personal exposimeters for measuring RF-EMF exposure may be considered impractical for large epidemiological studies, which require large organizational effort and resources. The handling of exposimeters is a demanding and time-consuming task for the study participants, which would likely deter many of them from participating, thus possibly introducing participation bias. Study participants might even manipulate the measurements by 
placing the exposimeter at positions where high RF-EMF exposures are expected, which would yield unreliable results. Moreover, exposimeters are not feasible for collecting information on long-term exposure, i.e. over several years, or on past exposure. Previous epidemiological studies have utilized other exposure assessment methods to estimate RFEMF exposure which include spot measurements in bedrooms (Berg-Beckhoff et al., 2009; Hutter et al., 2006; Tomitsch et al., 2009), self-reported (Navarro et al., 2003; Santini et al., 2003) or geo-coded distance of the residence to the closest mobile phone base station (Blettner et al., 2009), and geospatial modeling of broadcast transmitters or mobile phone base stations (Bürgi et al., 2010; Bürgi et al., 2008; Ha et al., 2007; Neitzke et al., 2007). However, it is unclear how well these methods represent personal exposure to all relevant sources of RF-EMF in everyday life.

This paper summarizes comprehensive RF-EMF exposure data collected from 166 participants in the QUALIFEX study, a prospective cohort study examining exposure to radio frequency electromagnetic field exposure and health related quality of life. The aims of this study were to determine the impact of personal mobile phone use on personal RF-EMF measurements and to evaluate how reliably different exposure assessment methods could represent personal exposure. 


\section{Methods}

\subsection{Personal measurements with exposimeters}

A detailed description of the recruitment of the participants and measurement protocols are summarized previously in Frei et al. (2009b). In brief, RF-EMF measurements were collected from 166 volunteers living in the city of Basel (Switzerland) and its surroundings between April 2007 and February 2008. RF-EMF exposure was measured using the personal exposimeter EME Spy 120 (SATIMO, Courtaboeuf, France, http://www.satimo.fr/). The study participants carried an exposimeter during one week and completed a time activity diary, specifically recording place of stay and detailed use of cordless and mobile phones. In addition, each participant completed a questionnaire regarding exposure relevant factors and characteristics. In order to maximize the range of exposure levels, 35 volunteers that were expected to have a high residential exposure to mobile phone base stations $(n=27)$ or broadcast transmitters $(n=8)$ were recruited. The remaining 131 volunteers were not specifically selected. Ethical approval for the conduct of the study was received from the ethical committee of Basel on March 19th, 2007 (EK: 38/07).

The exposimeter measured exposure from twelve frequency bands every 90 seconds: radio FM (frequency modulation; 88-108 MHz), TV (television, 174-223 MHz and 470-830 MHz), Tetrapol (terrestrial trunked radio police; 380-400 MHz), uplink in three frequency ranges (communication from mobile phone handset to base station; 880-915, 1710-1785, 1920-1980 MHz), downlink in three frequency ranges (communication from mobile phone base station to handset; 925-960, 1805-1880, 2110-2170 MHz), DECT (digital enhanced cordless telecommunications; 1880-1900 MHz) and W-LAN (wireless local area network; 2400-2500 MHz). The median number of recorded measurements per person was 6472 . For each individual, a weekly arithmetic mean value was calculated for each frequency band using the robust regression on order statistics (ROS) method allowing for measurements 
below the detection limit of $0.0067 \mathrm{~mW} / \mathrm{m}^{2}$ (Röösli et al., 2008). Exposure to all measured frequency bands was derived by summing up the values of all frequency bands.

Measurements that occurred during use of personal mobile or cordless phones, identified by means of the personal diary, were omitted from the calculation of mean values. To evaluate the impact of personal mobile and cordless phone use on mean values, the calculation of the mean was also derived from values of all measurements. From this point forward, these mean values are referred to as mean values without and with personal phone use.

\subsection{Spot measurements in bedroom}

Spot measurements were performed in the bedrooms of 134 study participants using a NARDA SRM-3000 radiation meter. Spot measurements were not performed for the remaining 32 participants due to technical and organizational difficulties. The NARDA device measured the same frequency bands as the exposimeter (Table 1). The measurements were taken as temporal averages with the root-mean-square-mode of the radiation meter. We measured 7 points per room, with the first three points in the centre of the bedroom at $1.1 \mathrm{~m}$, $1.5 \mathrm{~m}$ and $1.7 \mathrm{~m}$ above the floor. Four additional points were arranged in a rectangle, each at 1 $\mathrm{m}$ from the centre towards a corner of the room, $1.5 \mathrm{~m}$ above ground.

\subsection{Geo-coded distance to the closest fixed transmitter}

The geographical coordinates of the participants' residencies were identified by the Swiss Federal Statistical Office, and the horizontal distance of the residence to the closest fixed site transmitter (mobile phone base station or broadcast transmitter) was calculated for each study participant. To exclude microcells, only transmitters with an effective radiated power of more than 15 Watt were considered. Geo-coded distance was not calculated for one person who lived across the Swiss border. 


\subsection{Geospatial propagation model}

We used a three-dimensional geospatial propagation model for the study area in which RF-EMF from fixed site transmitters (frequency bands are shown in Table 1) was modeled (in- and outside of buildings) (Bürgi et al., 2010; Bürgi et al., 2008). The model calculation was based on a comprehensive database of all transmitters (position, transmission direction, antenna types and radiation pattern, transmitter power and number of channels) and a threedimensional building model of the study area, considering shielding and diffraction by buildings and topography. Using the geographical coordinates of the participants' residencies and the information about the floor level of the participants' apartments, mean RF-EMF in a horizontal radius of five meters around the coordinate at home was determined for each study participant, with exception for two participants who lived outside of the area covered by the model.

\subsection{Full exposure prediction model}

An exposure prediction model for personal RF-EMF exposure measured by the exposimeters was developed based on the exposure questionnaire and the modeled RF-EMF from the geospatial propagation model at the participants' residencies. The procedure for the model development and validation is summarized in detail in Frei et al. (2009a). Briefly, we identified the following relevant exposure predictors using multiple regression models: the modeled RF-EMF at the participants' home from the geospatial propagation model, modified by the type of house wall and type of window frames. Additionally, the ownership of communication devices (W-LAN, mobile and cordless phones) and behavioral characteristics (amount of time spent in public transport vehicles or cars, percent full-time equivalent) were included into the model. For the two study participants for whom the value of the geospatial propagation model was missing the measured RF-EMF was used. 


\subsection{Self-estimated exposure}

In the exposure questionnaire, participants were asked about self-estimated exposure in comparison to the general Swiss population (separately for the sources radio FM / TV broadcast, mobile phone base stations and handsets, cordless phones and W-LAN as well as for all of these sources combined). The participants had to rate whether they considered themselves to be less, equally or more exposed compared to the average Swiss population. As nine study participants did not respond to this question, we obtained data on self-estimated exposure from 157 study participants.

\subsection{Statistical analyses}

Statistical analyses were carried out using STATA version 10.1 (StataCorp, College Station, TX, USA) and R version 2.9.1. All calculations were performed with the values for the power flux density $\left(\mathrm{mW} / \mathrm{m}^{2}\right)$. Spearman rank correlations $\left(\mathrm{r}_{\mathrm{s}}\right)$ were estimated between the values obtained using the different exposure assessment methods and the personal measurements and between the mean values of the different exposure sources (derived from the exposimeter measurements). We applied linear regression models to quantify the impact of personal mobile and cordless phone use on mean values obtained from the exposimeter measurements. 


\section{Results}

\subsection{Study participants}

The characteristics of the study participants are shown in Table 2. The mean age was 42.6 years and 92 of the participants $(55 \%)$ were women. The majority of the study participants owned mobile and cordless phones (88\% and $72 \%$, respectively) and approximately one third owned a W-LAN at home. The average length of mobile and cordless phone use per week recorded in the personal diaries were 17 and 42 minutes, respectively.

\subsection{Contribution of personal mobile and cordless phone use to individual RF-EMF exposure}

Figure 1 a) shows scatter plots of the association between mobile phone use and mean values of all 3 uplink bands combined with (solid slopes) and without (dashed slopes) personal phone calls and Figure $1 \mathrm{~b}$ ) shows the corresponding data for the cordless phone use. Mean personal exposure to uplink (with personal phone use) increased by $0.038 \mathrm{~mW} / \mathrm{m}^{2}$ (95\%-CI: 0.022 to $0.054 \mathrm{~mW} / \mathrm{m}^{2}$; intercept: $0.034 \mathrm{~mW} / \mathrm{m}^{2}$ ) per hour of mobile phone use and exposure to DECT cordless phones by $0.023 \mathrm{~mW} / \mathrm{m}^{2}$ (95\%-CI: 0.012 to $0.033 \mathrm{~mW} / \mathrm{m}^{2}$; intercept: $0.026 \mathrm{~mW} / \mathrm{m}^{2}$ ) per hour of cordless phone use. Exposure over all frequency bands (total exposure; data not shown) increased by $0.026 \mathrm{~mW} / \mathrm{m}^{2}$ (95\%-CI: -0.025 to 0.077 $\mathrm{mW} / \mathrm{m}^{2}$ ) per hour of mobile phone use and by $0.027 \mathrm{~mW} / \mathrm{m}^{2}$ (95\%-CI: 0.009 to 0.046 $\mathrm{mW} / \mathrm{m}^{2}$ ) per hour of cordless phone use. In case of mobile phone use without personal phone use, exposure to uplink increased by $0.023 \mathrm{~mW} / \mathrm{m}^{2}\left(95 \%\right.$-CI: 0.007 to $0.038 \mathrm{~mW} / \mathrm{m}^{2}$ ) per hour of mobile phone use (Figure 1 a). The corresponding increase in the DECT band was 0.009 $\mathrm{mW} / \mathrm{m}^{2}\left(-0.001\right.$ to $\left.0.018 \mathrm{~mW} / \mathrm{m}^{2}\right)$ per hour of cordless phone use (Figure $1 \mathrm{~b}$ ). Total exposure calculated without personal phone use increased by $0.010 \mathrm{~mW} / \mathrm{m}^{2}(95 \%-\mathrm{CI}$ : -0.039 to 0.058 
$\left.\mathrm{mW} / \mathrm{m}^{2}\right)$ per hour of mobile phone use and by $0.013 \mathrm{~mW} / \mathrm{m}^{2}(95 \%-\mathrm{CI}:-0.005$ to 0.031 $\mathrm{mW} / \mathrm{m}^{2}$ ) per hour of cordless phone use.

Figure 2 shows the mean values and contributions of the different sources with (Figure 2 a) and without (Figure 2 b) personal phone use. The mean values over all frequency bands were $0.15 \mathrm{~mW} / \mathrm{m}^{2}$ with personal phone use compared to $0.13 \mathrm{~mW} / \mathrm{m}^{2}$ without personal phone use and this difference is statistically significant (t-test, $\mathrm{p}<0.001)$. The increase of $12.4 \%$, when including measurements during personal phone use, was mainly influenced by the use of cordless phones $(64.2 \%)$. The contribution of the uplink band to total exposure was $29.8 \%$ with personal phone use. Without personal phone use the contribution of uplink was $29.1 \%$. Exposure to DECT phones contributed $27.8 \%$ to total exposure when measurements during personal cordless phone calls were included and $22.7 \%$ when such measurements were excluded. The Spearman correlation between the mean values with and without personal phone use was 0.94 (95\%-CI: 0.92 to 0.96$)$ (Table 3).

\subsection{Exposure assessment methods: characteristics and correlations}

Figure 3 a) to e) show box plots of the personal measurements over all frequency bands (without personal phone use) for three categories of the alternative exposure assessment methods and the corresponding Spearman correlation coefficients. Table 3 shows the characteristics of the different exposure assessment methods as well as the $95 \%$ confidence intervals of the Spearman correlation coefficients. The mean values derived from the personal measurements (with and without personal phone use), from the spot measurements, and the geospatial propagation and the full exposure prediction model were very similar (Table 3). The exposure range was smallest for the full exposure prediction model (between 0.03 and $0.55 \mathrm{~mW} / \mathrm{m}^{2}$ ) and largest for the spot measurements in the bedrooms of the study participants (between 0.00 and $3.53 \mathrm{~mW} / \mathrm{m}^{2}$ ). The average distance of the study participants' residences to the closest transmitter was 208 meters. The majority of the study participants $(65 \%)$ 
considered themselves to be equally exposed to RF-EMF compared to the average Swiss population.

The spot measurements, geospatial propagation model and full exposure prediction model were observed to be associated with the personal measurements without personal phone use (Figure 3 a), c) and d), respectively), and the corresponding Spearman correlation coefficients were 0.42 (95\%-CI: 0.27 to 0.55$), 0.28$ (95\%-CI: 0.14 to 0.42$)$, and 0.50 (95\%CI: 0.37 to 0.61 ), respectively. No associations were observed between personal exposimeter measurements and either the geo-coded distance to the closest fixed site transmitter or selfestimated exposure (Figures $3 \mathrm{~b}$ ) and e), respectively). The lack of association was reflected in a low Spearman rank correlation (Table 3) for geo-coded distance $\left(\mathrm{r}_{\mathrm{s}}=-0.03\right.$ (95\%-CI: -0.18 to 0.12$)$ and for self-estimated exposure $\left(\mathrm{r}_{\mathrm{s}}=0.06\right.$ (95\%-CI: -0.10 to 0.21$)$.

Of note, some of these exposure assessment methods were not intended to directly represent total personal RF-EMF exposure, but rather specific exposures situations, such as residential exposure. The geo-coded distance of the residence to the closest fixed site transmitter at home is expected to represent exposure to fixed site transmitters at home. The corresponding correlation between the geo-coded distance and residential exposure to fixed site transmitters measured by the exposimeter was -0.26 (95\%-CI: -0.39 to -0.11$)$. The mean residential exposure to fixed site transmitters was calculated using the respective exposimeter measurements at home during the measurement week, identified by the personal diary. Similarly, the correlation between mean personal exposure to fixed site transmitters and the calculated value obtained from the geospatial propagation model was 0.71 (95\%-CI: 0.63 to 0.78). The correlation between spot measurements and personal exposure measurements in the bedroom was 0.73 (95\%-CI: 0.63 to 0.80$)$. 


\subsection{Correlations of the different exposure sources}

By using the personal exposimeter measurements, we assessed the correlations of the different frequency bands with total exposure and with each other. Total exposure correlated best with exposure to mobile phone handsets $\left(\mathrm{r}_{\mathrm{s}}=0.42 ; 95 \%\right.$-CI: 0.29 to 0.54$)$, mobile phone base stations ( $r_{s}=0.38$; 95\%-CI: 0.24 to 0.50$)$ and cordless phones $\left(r_{s}=0.37 ; 95 \%\right.$-CI: 0.23 to 0.49). These were also the sources that contributed most to total mean exposure (Frei et al., 2009b). The Spearman correlations among the different frequency bands were low, with the highest positive correlation between exposure to W-LAN and mobile phone handsets $\left(r_{s}=0.21 ; 95 \%\right.$-CI: 0.06 to 0.35$)$ and the most negative correlation between exposure to cordless phones and mobile phone handsets $\left(r_{s}=-0.15\right.$; $95 \%-C I:-0.30$ to 0.00$)$. The correlation between exposure to mobile phone handsets and mobile phone base stations was 0.07 (95\%CI: -0.09 to 0.22$)$. 


\section{Discussion}

This study evaluated multiple exposure assessment methods for estimating personal exposure to environmental far-field RF-EMF. Personal mobile and cordless phone use were observed to contribute relatively little to the personal RF-EMF measurements, and geo-coded distance to the closest fixed site transmitter and the self-estimated exposure were shown to be inappropriate surrogates for personal RF-EMF exposure. The highest correlation with personal measurements was found for the full exposure prediction model, which takes into account modeled exposure at home and behavioral characteristics of a person, followed by spot measurements in the bedroom and the geospatial propagation model.

\subsection{Strengths and limitations}

This study consisted of a comprehensive exposure data collection, where approximately 6500 exposimeter measurements were collected over one entire week for 12 different frequency bands per person. In addition, we performed spot measurements, calculated the distance of the residence to the closest fixed site transmitter, collected data on self-estimated exposure, and developed a geospatial propagation model for the study region and a prediction model including personal characteristics. The multiple methods employed for exposure assessment allowed for direct comparison of the different methods, and to the authors' knowledge such an extensive comparison has not been conducted before. The Spearman correlation allowed for evaluating the reliability of the exposure assessment methods to classify exposure levels, and the ranking of exposure levels may be more essential than the correctness of absolute values in epidemiological studies (Neubauer et al., 2007).

Exposimeter measurements require a large organizational effort, thus a small sample size in this study is a primary limitation. In addition, personal exposimeter measurements served as measure of comparison, and measurement accuracy for the different frequency bands may be uncertain. A previous analysis observed that the accuracy of personal 
exposimeter measurements depended on specific configurations of different services generating different modulations of the signal and that cross-talks between bands may occur (Lauer et al., submitted for publication). In addition, shielding of the body might be of concern and depends on the body mass of a person (Knafl et al., 2008; Neubauer et al., 2008). We tried to minimize this problem by advising the study participants to place the exposimeters in their vicinity, but not directly on the body, when not moving.

To our knowledge, personal exposimeters include the most relevant RF-EMF sources. However, there are additional sources in the radio frequency range which were not considered. Our spot measurements included three additional frequency bands (paging services (147-148 MHz), DAB channel 12 (digital audio broadcast; 223-230 MHz) and GSMRail (mobile communication for the railway; 921-925 MHz)). The average contribution of these sources was small (3.3\%). We are not aware of other sources in the everyday environment which could have made a relevant contribution to total RF-EMF at the time of the measurement period (in the frequency range of $88-2500 \mathrm{MHz}$ ).

\subsection{Personal exposure measurements of sources operating close to the body}

Mobile and cordless phone radiation is an important exposure source also when personal phone use is omitted from the calculation of mean values (Figure $2 \mathrm{~b}$ ). The high contribution of mobile phone radiation may be mainly explained by the passive exposure from other persons using mobile phones. Also, handovers of the personal mobile phone from

one base station to another may be of influence. For cordless phones, the constant radiation of most available cordless phone base stations and cordless phone calls from other persons are explanations for the high contribution.

Exposure to uplink and DECT radiation as well as total exposure increased with increasing use of mobile and cordless phones even if calculated without personal phone use. There are several explanations for this: firstly, some phone calls may not have been noted in 
the diary, and this might correlate with the amount of phone use. Secondly, regular mobile and cordless phone users might spend more time at crowded places or with persons with similar behaviors in terms of phone use and thus have a higher background exposure to mobile and cordless phone radiation. Thirdly, with regard to exposure to mobile phones, regular mobile phone users might spend more of their time on the way, for example in trains, which leads to more carry-overs of the personal mobile phone. Fourthly, with regard to exposure to cordless phone use, regular cordless phone users might be near radiating DECT base stations more often.

The high Spearman correlation between the personal measurements with and without personal phone use $\left(r_{\mathrm{s}}=0.94\right)$ suggests that mean values derived from all personal measurements including personal phone use do reliably discriminate between participants' exposure levels to environmental far-field sources. This poses an advantage because not having to collect data on phone use reduces the effort for study participants as well as for data management. Although the absolute difference between the two mean total values was small, it was statistically significant. Hence, in a study where one intends to characterize typical exposure levels to environmental far-field sources in a certain population (instead of just differentiating between highly and lowly exposed categories), the use of personal mobile and cordless phones is not negligible. Although small on average, personal mobile and cordless phone use can reach substantial contributions for heavy phone users.

\subsection{Evaluation of the exposure assessment methods for epidemiological purposes}

In addition to the basic prerequisite to reliably discriminate between participants' exposure levels that an exposure assessment method has to fulfill, there are other aspects which have to be considered for the use in epidemiological studies. Participation bias is of concern. It can be introduced if an exposure assessment method requires active participation from potential study participants, and it is expected to be specifically pronounced if a large 
effort for study participants is involved. In this case, a substantial part of the study participants might refuse to participate, which may be of major of concern if participation is related to both health and exposure status (Bakke et al., 1990; de Marco et al., 1994; Röösli, 2008). Collecting exposimeter measurements in combination with diary data is likely to introduce participation bias because of the large effort required for study participants. Spot measurements in bedrooms also rely on compliance of study participants; however, a smaller effort is required. The full exposure prediction model relies on compliance from study participants because it requires questionnaire data from the participants. The effort for completing a questionnaire, however, is highly reduced compared to collecting personal exposimeter measurements. The use of a geospatial propagation model or of the geo-coded distance to the closest fixed site transmitter may be more ideal, because participants do not have to be contacted in order to assess exposure. Our results suggest, however, that the geocoded distance cannot reliably represent personal exposure. This is in line with previous studies in which the geo-coded distance was compared to spot measurements in the bedroom or personal measurements over 24 hours (Bornkessel et al., 2007; Breckenkamp et al., 2008; Radon et al., 2006). However, we found a moderate correlation between the geo-coded distance and residential exposure from fixed site transmitters $\left(\mathrm{r}_{\mathrm{s}}=-0.26(95 \%-\mathrm{CI}:-0.39\right.$ to $0.11)$.

Another issue regarding epidemiological studies is information bias. Information bias can be introduced if an exposure assessment method relies on subjective information of the study participants, and if objective exposure data is collected simultaneously with data on health because participants might be aware of the aim of the study. Self-estimated exposure is particularly prone to information bias. That self-estimated exposure is not correlated with actual personal exposure may imply that study participants are not aware of their own RFEMF exposure status and that they may be considered to be blinded to exposure. Therefore, evaluating self-estimated exposure can offer evidence for the occurrence of information bias 
and/or of a nocebo effect (which is the inverse of the placebo effect and means that adverse symptoms occur due to expectations (e.g. due to concerns)) (Röösli, 2008). In general, exposure assessment methods which are not based on subjective components are preferred and using the geo-coded distance to the closest fixed site transmitter or a geospatial propagation model fulfill this criterion ideally from this perspective. The full exposure prediction model relies on subjective information of the study participant; however, our model variables relate to statements about the ownership of wireless devices which are unlikely to be heavily biased or predictors which are unlikely to be related to RF-EMF exposure by lay persons (e.g. type of house wall).

The cost and feasibility of an exposure assessment method are also important criteria which have to be taken into account. Methods which involve high costs and workforce are personal exposimeter measurement studies or spot measurements. Typically, only a limited number of study participants can be included in such studies. The development of a geospatial or full exposure prediction model can be costly. Once developed, however, they are applicable for large study populations. The exposure assessment methods which involve low costs are the geo-coded distance or self-estimated exposure.

To date, no information is available on what biological mechanism is relevant for RFEMF below the standard limits. Scientific evidence has not suggested a health effect resulting from one specific exposure source or type of modulation (Neubauer et al., 2007; Schüz and Mann, 2000). Therefore, we consider it reasonable to take into account exposure from all relevant exposure sources. Our results show that no single exposure source is highly correlated with exposure over all frequency bands, and that the different exposure sources do not correlate with each other. Not including all relevant sources in an epidemiological study would therefore introduce a considerable random error which would lead to a substantial loss of power and to an underestimation of the true exposure-response association (Neubauer et al., 2007). However, it cannot be ruled out that future research might discover that effects are 
caused by specific exposure sources or that humans are specifically susceptible to RF-EMF during certain times of the day, e.g. during night. If this is the case, a re-evaluation of the exposure assessment methods will have to be conducted. 


\section{Conclusions}

This study provides new insight about the interpretation of different exposure assessment methods used in previous studies. Our data suggest that a reliable discrimination of personal exposure levels to environmental far-field RF-EMFs measured with exposimeters is also made when measurements during personal mobile and cordless phone use are included. The evaluation of other exposure assessment methods showed that spot measurements at home or modeling exposure from fixed site transmitters are conceivable surrogates for personal exposure, particularly for residential exposure. Optimally, data on residential exposure are combined with personal characteristics, as done in our full exposure prediction model. Using the geo-coded distance to the closest fixed site transmitter or self-estimated exposure is inappropriate, but the latter can provide information on a possible information bias or nocebo effect. Due to the rapid change of the technological development, the exposure situation in the everyday environment is expected to change substantially in the future, which means that the use of different exposure assessment methods will have to be re-evaluated. 


\section{ACKNOWLEDGEMENTS}

We thank Matthias Egger, Niklas Joos, Axel Hettich (QUALIFEX team) for inspiring discussions. We are thankful to René Denzler from Computer Controls AG for technical support with the exposimeters and to Frédéric Pythoud from METAS (federal office of metrology) for the calibration service. Many thanks go also to all study participants who volunteered for the study.

\section{Funding}

This study is funded by the Swiss National Science Foundation (Grant 405740113595). It is part of the National Research Program 57 "Non-Ionising Radiation - Health and Environment". Martin Röösli is supported by the Swiss School of Public Health + (SSPH+).

\section{Conflict of interest}

The authors declare no conflict of interest. 


\section{References}

Bakke P, Gulsvik A, Lilleng P, Overa O, Hanoa R, Eide GE. Postal survey on airborne occupational exposure and respiratory disorders in Norway: causes and consequences of non-response. J Epidemiol Community Health 1990; 44:316-20.

Berg-Beckhoff G, Blettner M, Kowall B, Breckenkamp J, Schlehofer B, Schmiedel S, et al. Mobile phone base stations and adverse health effects: phase 2 of a cross-sectional study with measured radio frequency electromagnetic fields. Occup Environ Med $2009 ; 66: 124-30$.

Blettner M, Schlehofer B, Breckenkamp J, Kowall B, Schmiedel S, Reis U, et al. Mobile phone base stations and adverse health effects: phase 1 of a population-based, crosssectional study in Germany. Occup Environ Med 2009; 66:118-23.

Bornkessel C, Schubert M, Wuschek M, Schmidt P. Determination of the general public exposure around GSM and UMTS base stations. Radiat Prot Dosimetry 2007; 124:407.

Breckenkamp J, Neitzke HP, Bornkessel C, Berg-Beckhoff G. Applicability of an Exposure Model for the Determination of Emissions from Mobile Phone Base Stations. Radiat Prot Dosimetry 2008; 131:474-81.

Bürgi A, Frei P, Theis G, Mohler E, Braun-Fahrländer C, Fröhlich J, et al. A model for radiofrequency electromagnetic fields at outdoor and indoor locations for use in an epidemiological study. Bioelectromagnetics 2010; 31:226-36.

Bürgi A, Theis G, Siegenthaler A, Röösli M. Exposure modeling of high-frequency electromagnetic fields. J Expo Sci Environ Epidemiol 2008; 18:183-91.

de Marco R, Verlato G, Zanolin E, Bugiani M, Drane JW. Nonresponse bias in EC Respiratory Health Survey in Italy. Eur Respir J 1994; 7:2139-45. 
Frei P, Mohler E, Bürgi A, Fröhlich J, Neubauer G, Braun-Fahrländer C, et al. A prediction model for personal radio frequency electromagnetic field exposure. Sci Total Environ 2009a; 408:102-8.

Frei P, Mohler E, Neubauer G, Theis G, Bürgi A, Fröhlich J, et al. Temporal and spatial variability of personal exposure to radio frequency electromagnetic fields. Environ Res 2009b; 109:779-85.

Ha M, Im H, Lee M, Kim HJ, Kim BC, Gimm YM, et al. Radio-frequency radiation exposure from AM radio transmitters and childhood leukemia and brain cancer. Am J Epidemiol 2007; 166:270-9.

Hutter HP, Moshammer H, Wallner P, Kundi M. Subjective symptoms, sleeping problems, and cognitive performance in subjects living near mobile phone base stations. Occup Environ Med 2006; 63:307-13.

Inyang I, Benke G, McKenzie R, Abramson M. Comparison of measuring instruments for radiofrequency radiation from mobile telephones in epidemiological studies: implications for exposure assessment. J Expo Sci Environ Epidemiol 2008; 18:134-41. Joseph W, Vermeeren G, Verloock L, Heredia MM, Martens L. Characterization of personal RF electromagnetic field exposure and actual absorption for the general public. Health Phys 2008; 95:317-30.

Knafl U, Lehmann H, Riederer M. Electromagnetic field measurements using personal exposimeters. Bioelectromagnetics 2008; 29:160-2.

Kühnlein A, Heumann C, Thomas S, Heinrich S, Radon K. Personal exposure to mobile communication networks and well-being in children-A statistical analysis based on a functional approach. Bioelectromagnetics 2009; 30:261-9.

Lauer O, Neubauer G, Röösli M, Riederer M, Mohler E, Frei P, et al. Determination of correction factors for band-selective personal exposure meters: an example study. submitted for publication. 
Navarro EA, Segura J, Portolés M, de Mateo CGP. The microwave syndrome: a preliminary study in Spain. Electromagnetic Biology and Medicine 2003; 22:161-9.

Neitzke HP, Osterhoff J, Peklo K, Voigt H. Determination of exposure due to mobile phone base stations in an epidemiological study. Radiat Prot Dosimetry 2007; 124:35-9.

Neubauer G, Cecil S, Giczi W, Petric B, Preiner P, Fröhlich J, et al. Final Report on the Project C2006-07, Evaluation of the correlation between RF dosimeter reading and real human exposure. ARC-Report ARC-IT-0218, April 20082008.

Neubauer G, Feychting M, Hamnerius Y, Kheifets L, Kuster N, Ruiz I, et al. Feasibility of future epidemiological studies on possible health effects of mobile phone base stations. Bioelectromagnetics 2007; 28:224-30.

Radon K, Spegel H, Meyer N, Klein J, Brix J, Wiedenhofer A, et al. Personal dosimetry of exposure to mobile telephone base stations? An epidemiologic feasibility study comparing the Maschek dosimeter prototype and the Antennessa SP-090 system. Bioelectromagnetics 2006; 27:77-81.

Röösli M. Radiofrequency electromagnetic field exposure and non-specific symptoms of ill health: a systematic review. Environ Res 2008; 107:277-87.

Röösli M, Frei P, Mohler E, Braun-Fahrländer C, Bürgi A, Fröhlich J, et al. Statistical analysis of personal radiofrequency electromagnetic field measurements with nondetects. Bioelectromagnetics 2008; 29:471-8.

Santini R, Santini P, Ruz PL, Danze JM, Seigne M. Survey study of people living in the vicinity of cellular phone base stations. Electromagnetic Biology and Medicine 2003; 22:41-9.

Schüz J, Mann S. A discussion of potential exposure metrics for use in epidemiological studies on human exposure to radiowaves from mobile phone base stations. J Expo Anal Environ Epidemiol 2000; 10:600-5. 
Thomas S, Kühnlein A, Heinrich S, Praml G, Nowak D, von Kries R, et al. Personal exposure to mobile phone frequencies and well-being in adults: a cross-sectional study based on dosimetry. Bioelectromagnetics 2008; 29:463-70.

Thuróczy G, Molnár F, Jánossy G, Nagy N, Kubinyi G, Bakos J, et al. Personal RF exposimetry in urban area. Annals of Telecommunications 2008; 63:87-96.

Tomitsch J, Dechant E, Frank W. Survey of electromagnetic field exposure in bedrooms of residences in lower Austria. Bioelectromagnetics 2009; epub: 26.9.2009, :DOI: 10.1002/bem.20548.

Viel JF, Cardis E, Moissonnier M, de Seze R, Hours M. Radiofrequency exposure in the French general population: band, time, location and activity variability. Environ Int $2009 ; 35: 1150-4$.

Vrijheid M, Armstrong BK, Bedard D, Brown J, Deltour I, Iavarone I, et al. Recall bias in the assessment of exposure to mobile phones. J Expo Sci Environ Epidemiol 2009; 19:369-81. 


\section{Table captions}

Table 1: Description of the different exposure assessment methods

Table 2: Characteristics of the study participants.

Table 3: Characteristics of the different exposure assessment methods and Spearman correlations with the personal measurements (without personal phone use) 


\section{Figure captions}

Figure 1: Scatter plots and linear fits of mobile (a) phone use and mean exposure to uplink (UL) and cordless (b) phone use and mean exposure to DECT radiation obtained from the personal measurements. The black points represent mean values when personal mobile phone calls were included and the grey circles when such values were excluded. The solid and dashed slopes represent the linear regression line for the mean values with and without personal phone use, respectively. Note that the scale for the $\mathrm{x}$ and $\mathrm{y}$ axes are doubled in Figure $1 \mathrm{~b}$ compared to Figure $1 \mathrm{a}$. Therefore, the slopes of the two figures can directly be compared.

Figure 2: Mean exposure over one week and contributions from the different sources including (a) and omitting (b) measurements during personal mobile and cordless phone use from the calculation

Figure 3: Box plots of the different exposure assessment methods with the mean total exposure (without personal phone use) in $\mathrm{mW} / \mathrm{m}^{2}$ measured by the exposimeters. Exposure was classified into three groups $\left(<50^{\text {th }}\right.$ percentile, $50-90^{\text {th }}$ percentile, $>90^{\text {th }}$ percentile $)$ 


\section{Tables}

Table 1: Description of the different exposure assessment methods

\begin{tabular}{|c|c|c|c|}
\hline $\begin{array}{l}\text { Exposure } \\
\text { assessment method }\end{array}$ & Unit & Description & Exposure sources $^{\mathrm{a}}$ \\
\hline $\begin{array}{l}\text { Pers. measurements } \\
\text { w/o personal phone } \\
\text { use }\end{array}$ & $\mathrm{mW} / \mathrm{m}^{2}$ & $\begin{array}{l}\text { EME Spy } 120 \text { measurements } \\
\text { every } 90 \text { s during one week } \\
\text { without personal phone use }\end{array}$ & $\begin{array}{l}\text { FM, TV, Tetrapol, Uplink, } \\
\text { Downlink, DECT, W- } \\
\text { LAN }\end{array}$ \\
\hline $\begin{array}{l}\text { Pers. measurements } \\
\text { with personal phone } \\
\text { use }\end{array}$ & $\mathrm{mW} / \mathrm{m}^{2}$ & $\begin{array}{l}\text { EME Spy } 120 \text { measurements } \\
\text { every } 90 \text { s during one week } \\
\text { including all measurements }\end{array}$ & $\begin{array}{l}\text { FM, TV, Tetrapol, Uplink, } \\
\text { Downlink, DECT, W- } \\
\text { LAN }\end{array}$ \\
\hline Spot measurements & $\mathrm{mW} / \mathrm{m}^{2}$ & $\begin{array}{l}\text { 7-point-average NARDA } \\
\text { SRM-3000 spot } \\
\text { measurements in bedroom }\end{array}$ & $\begin{array}{l}\text { FM, TV, Tetrapol, Uplink, } \\
\text { Downlink, DECT, W- } \\
\text { LAN }\end{array}$ \\
\hline Geo-coded distance & $\mathrm{m}$ & $\begin{array}{l}\text { Geo-coded distance to the } \\
\text { closest fixed site transmitter } \\
(\mathrm{ERP}>15 \mathrm{~W})^{2}\end{array}$ & $\begin{array}{l}\text { FM, TV, Tetrapol, } \\
\text { Downlink }\end{array}$ \\
\hline $\begin{array}{l}\text { Geospatial } \\
\text { propagation model }\end{array}$ & $\mathrm{mW} / \mathrm{m}^{2}$ & $\begin{array}{l}\text { Three-dimensional model } \\
\text { (in- and outside buildings) } \\
\text { for fixed site transmitters }\end{array}$ & $\begin{array}{l}\text { FM, TV, Tetrapol, } \\
\text { Downlink }\end{array}$ \\
\hline $\begin{array}{l}\text { Full exposure } \\
\text { prediction model }\end{array}$ & $\mathrm{mW} / \mathrm{m}^{2}$ & $\begin{array}{l}\text { Prediction model based on } \\
\text { geospatial propagation model } \\
\text { and exposure relevant } \\
\text { behavior }\end{array}$ & $\begin{array}{l}\text { FM, TV, Tetrapol, Uplink, } \\
\text { Downlink, DECT, W- } \\
\text { LAN }\end{array}$ \\
\hline $\begin{array}{l}\text { Self-estimated } \\
\text { exposure }\end{array}$ & category & $\begin{array}{l}\text { Self-reported exposure in } \\
\text { comparison to the Swiss } \\
\text { population }\end{array}$ & $\begin{array}{l}\text { FM, TV, Uplink, } \\
\text { Downlink, } \\
\text { DECT, W-LAN }\end{array}$ \\
\hline \multicolumn{4}{|c|}{$\begin{array}{l}{ }^{a} \text { Frequency bands considered by the exposure methods: } \mathrm{FM}=\mathrm{FM} \text { radio broadcast transmitter; } \mathrm{TV}=\text { Television } \\
\text { broadcast transmitter; Tetrapol= Mobile communication system for closed groups, Uplink= Transmission from } \\
\text { mobile phone handset to base station, Downlink= Transmission from mobile phone base station to handset; } \\
\text { DECT=cordless phone, W-LAN= Wireless LAN. }\end{array}$} \\
\hline
\end{tabular}


Table 2: Characteristics of the study participants.

\begin{tabular}{cccc}
\hline Sex & Male & n & \% \\
\hline Female & 74 & 44.6 \\
& 92 & 55.4 \\
\hline Age (years) & & \\
\hline $18-34$ & 62 & 37.4 \\
$35-49$ & 50 & 30.1 \\
$50-64$ & 41 & 24.7 \\
$>64$ & 13 & 7.8 \\
\hline
\end{tabular}

\section{Ownership of wireless devices at home}

Persons owning a mobile phone handset $143 \quad 87.7$

$\begin{array}{lll}\text { Persons owning a cordless phone } & 118 & 72.4\end{array}$

$\begin{array}{lll}\text { Persons owning W-LAN } & 55 & 33.7\end{array}$

\begin{tabular}{lcc}
\hline Use of mobile phone & & \\
\hline No use & 65 & 39.2 \\
$\quad 1$ minute - 1 hour & 53.0 \\
$>1$ hour & 13 & 7.8 \\
\hline Use of cordless phone & 61 & 36.8 \\
\hline No use & 66 & 40.9 \\
1 minute - 1 hour & 36 & 22.3 \\
\hline 1 hour & & \\
\hline
\end{tabular}


Table 3: Characteristics of the different exposure assessment methods and Spearman correlations with the personal measurements (without personal phone use)

\begin{tabular}{|c|c|c|c|c|c|c|}
\hline $\begin{array}{l}\text { Exposure assessment } \\
\text { method }\end{array}$ & n & Mean & Min & Max & $\begin{array}{l}\text { Correlation } \\
\text { (Spearman) }\end{array}$ & $95 \%$-CI \\
\hline $\begin{array}{l}\text { Personal measurements } \\
\text { without personal phone } \\
\text { use }\end{array}$ & 166 & 0.13 & 0.01 & 0.88 & 1 & $(-)$ \\
\hline $\begin{array}{l}\text { Personal measurements } \\
\text { with personal phone use }\end{array}$ & 166 & 0.15 & 0.02 & 0.89 & 0.94 & $(0.92 ; 0.96)$ \\
\hline Spot measurements & 134 & 0.11 & 0.00 & 3.53 & 0.42 & $(0.27 ; 0.55)$ \\
\hline Geo-coded distance & 165 & 208 & 4 & 1026 & -0.03 & $(-0.18 ; 0.12)$ \\
\hline $\begin{array}{l}\text { Geospatial propaga- } \\
\text { tion model }\end{array}$ & 164 & 0.14 & 0.00 & 2.01 & 0.28 & $(0.14 ; 0.42)$ \\
\hline \multirow[t]{2}{*}{$\begin{array}{l}\text { Full exposure predict- } \\
\text { tion model }\end{array}$} & 166 & 0.12 & 0.03 & 0.55 & 0.50 & $(0.37 ; 0.61)$ \\
\hline & & equal $^{\mathrm{a}}$ & lower $^{\mathrm{a}}$ & higher $^{\text {a }}$ & & \\
\hline $\begin{array}{l}\text { Self-estimated } \\
\text { exposure }\end{array}$ & 157 & $\begin{array}{c}102 \\
(65 \%)\end{array}$ & $\begin{array}{c}37 \\
(24 \%)\end{array}$ & $\begin{array}{c}18 \\
(11 \%)\end{array}$ & 0.06 & $(-0.10 ; 0.21)$ \\
\hline
\end{tabular}

${ }^{\mathrm{a}}$ in comparison to the general Swiss population 
Figure 1

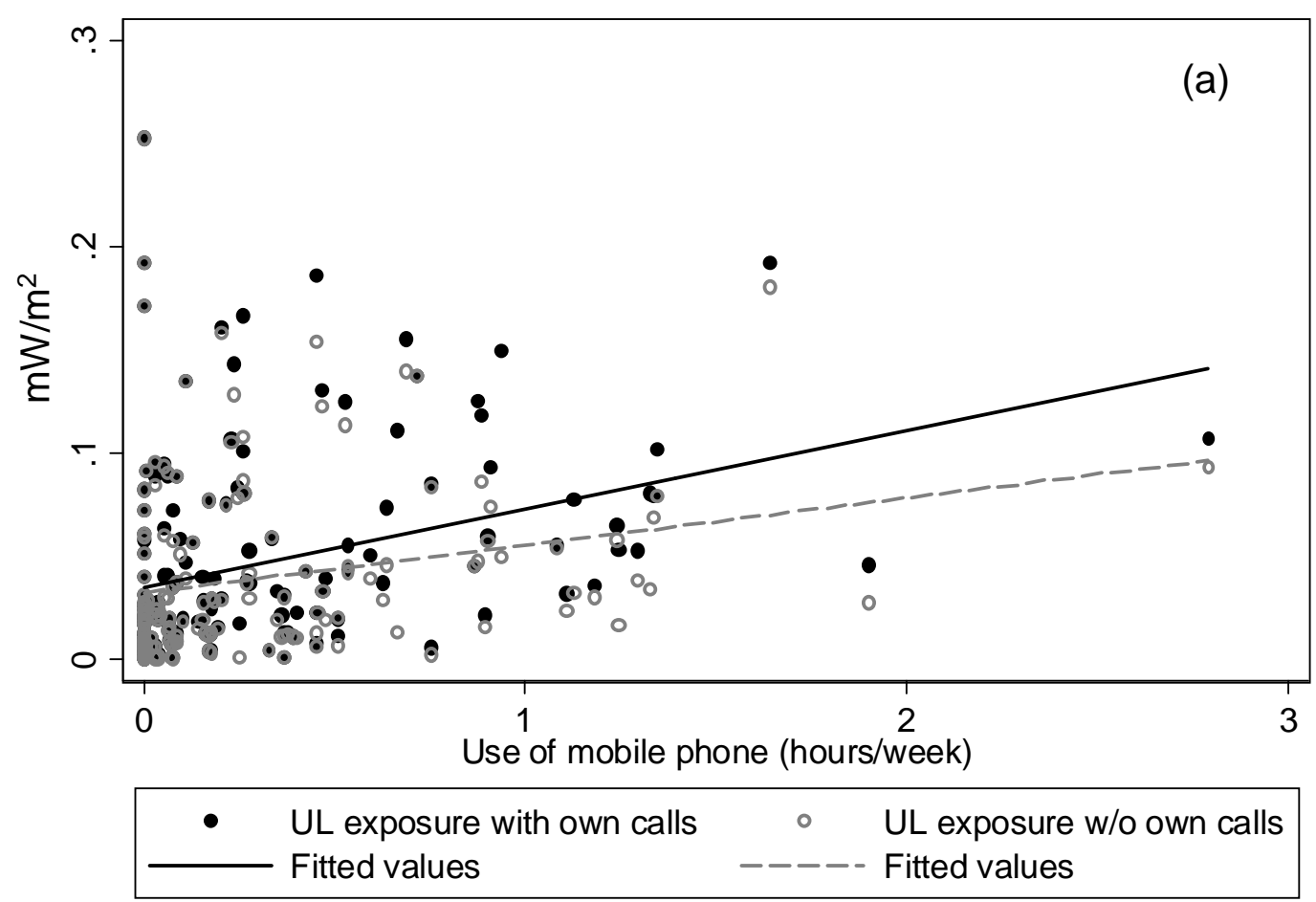




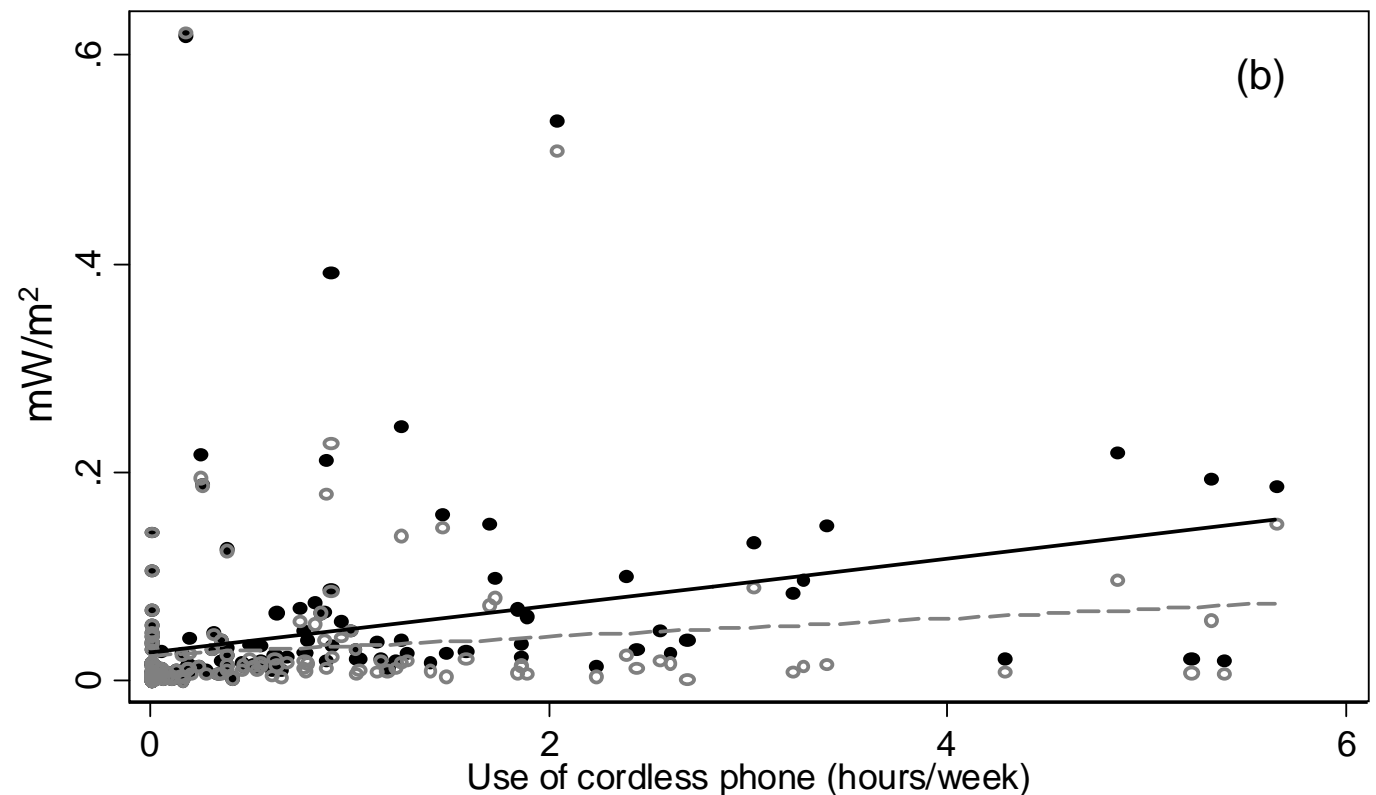

Use of cordless phone (hours/week)

$\begin{array}{clcl}- & \text { DECT exp. with own calls } & \circ & \text { DECT exp. w/o own calls } \\ \text { Fitted values } & ----- & \text { Fitted values }\end{array}$


Figure 2

(a)

(b)

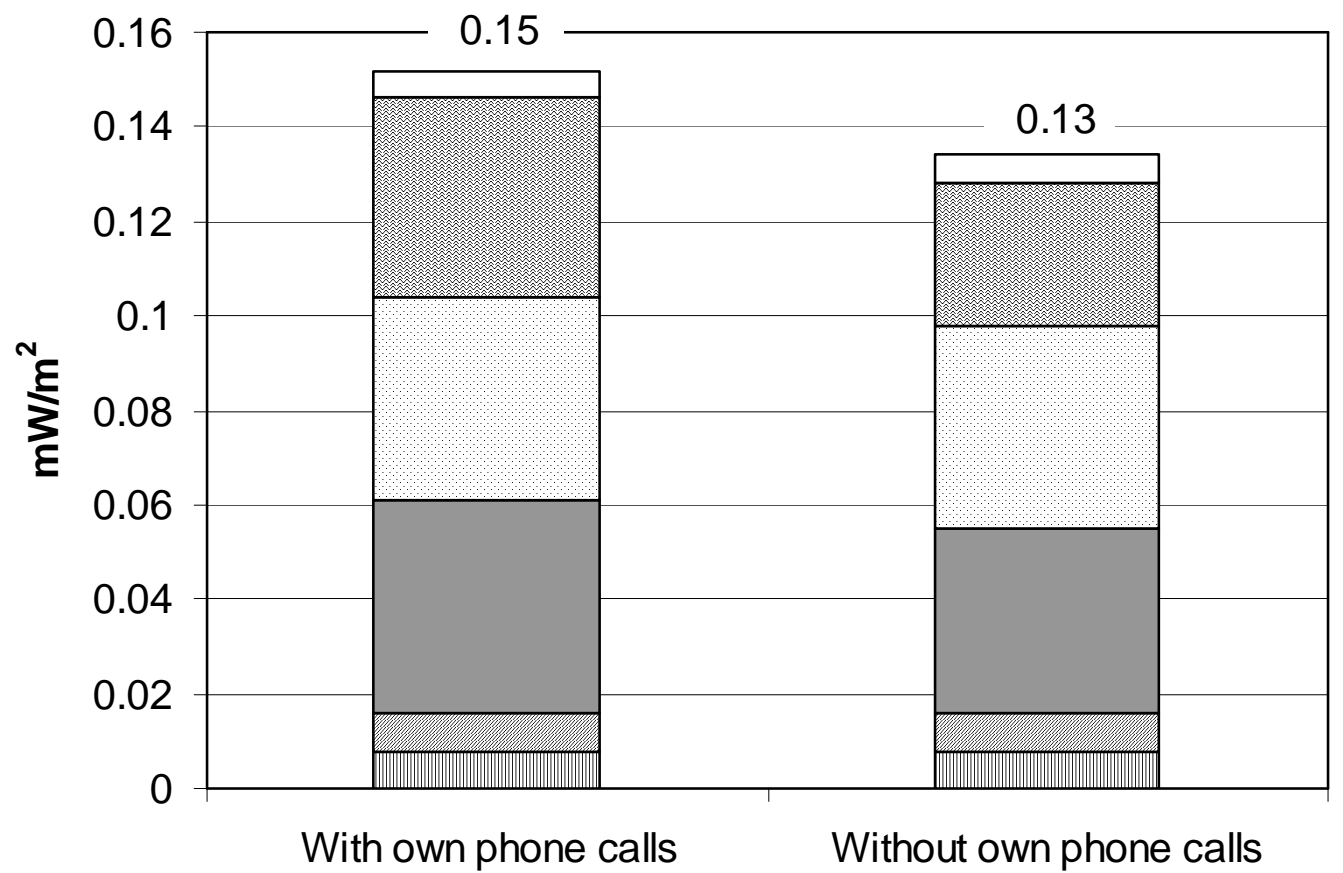

圆FM 圆TV 图Tetrapol $\square$ Uplink $\square$ Downlink 圆 DECT $\square$ W-LAN 
Figure 3

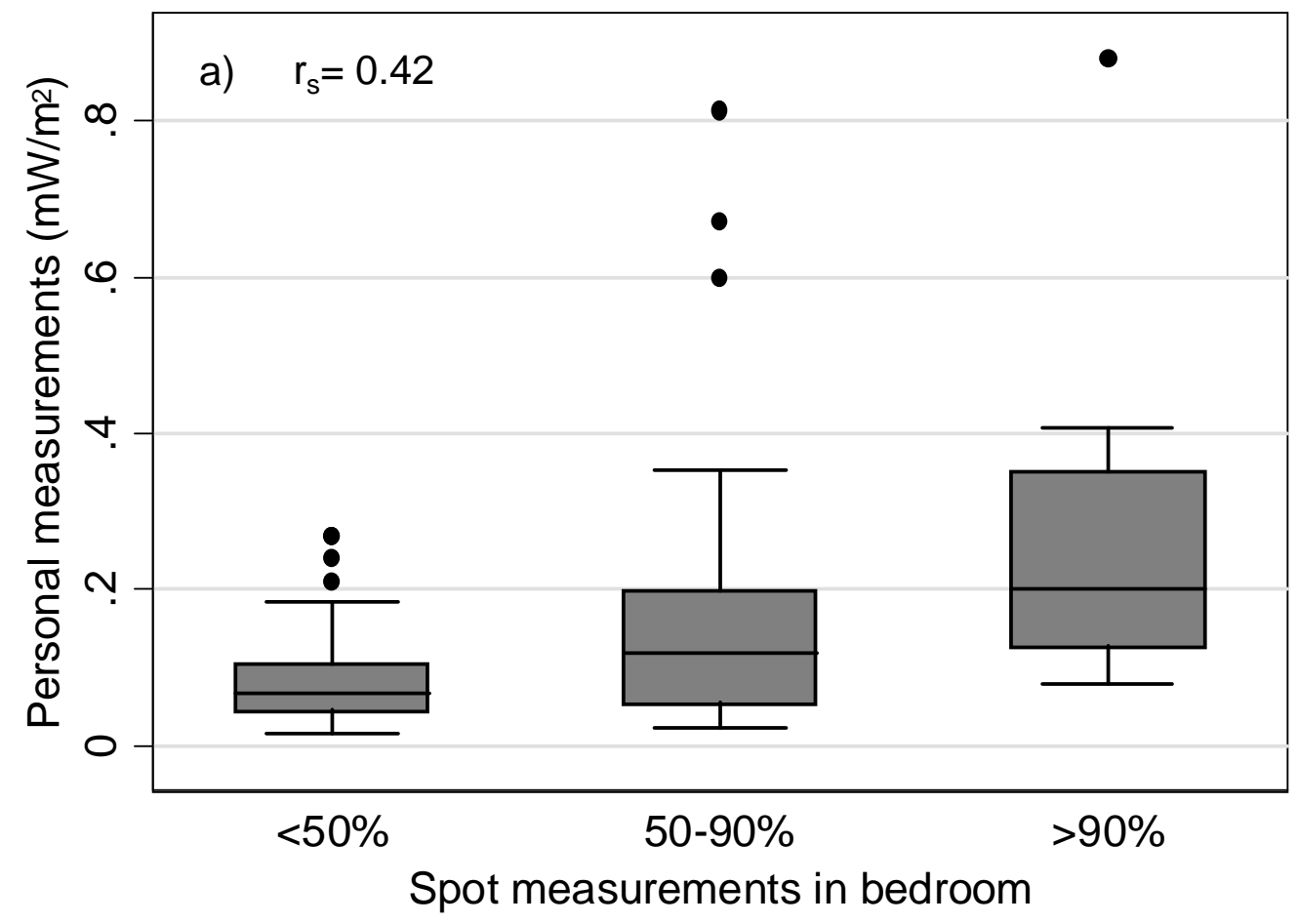




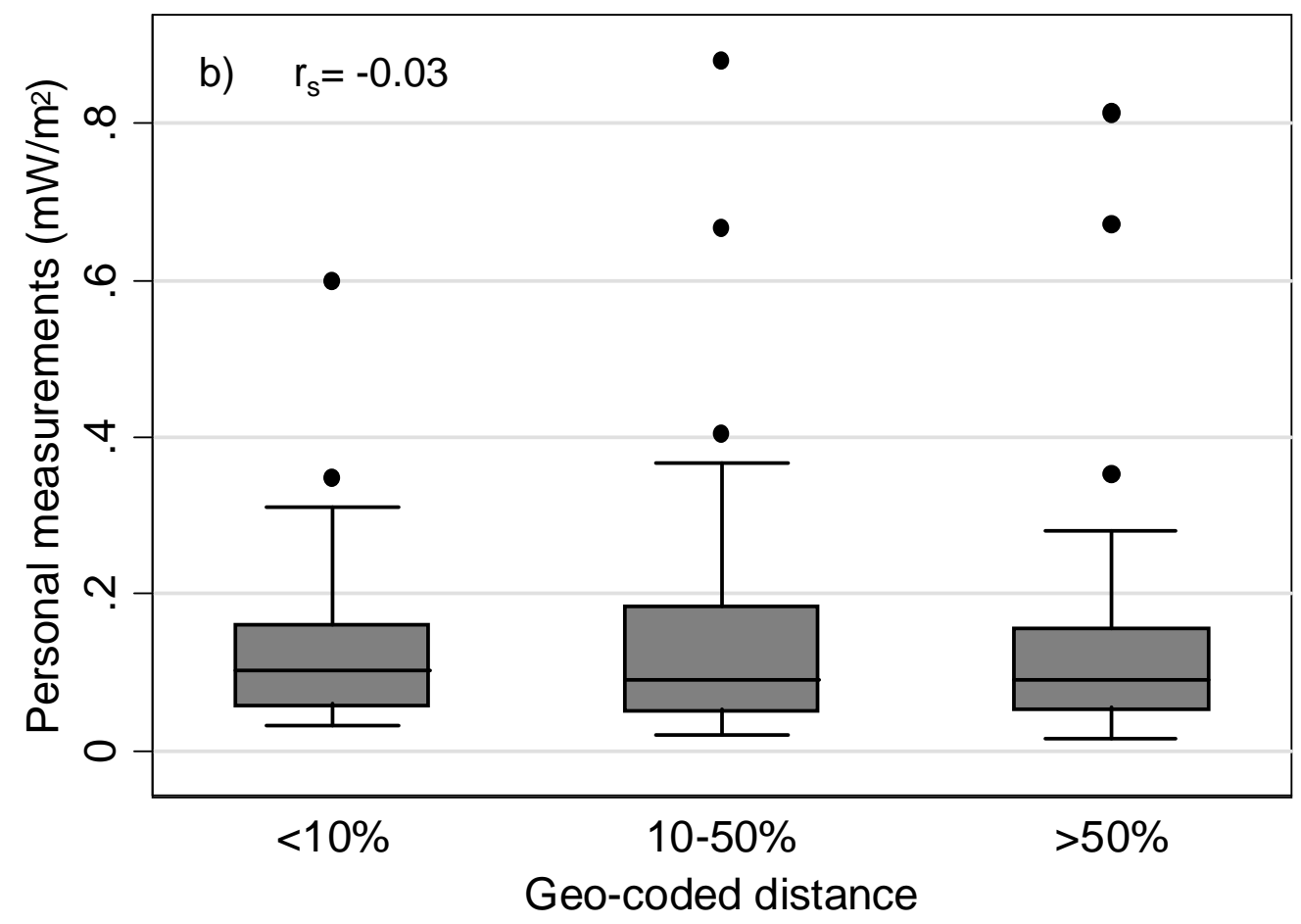




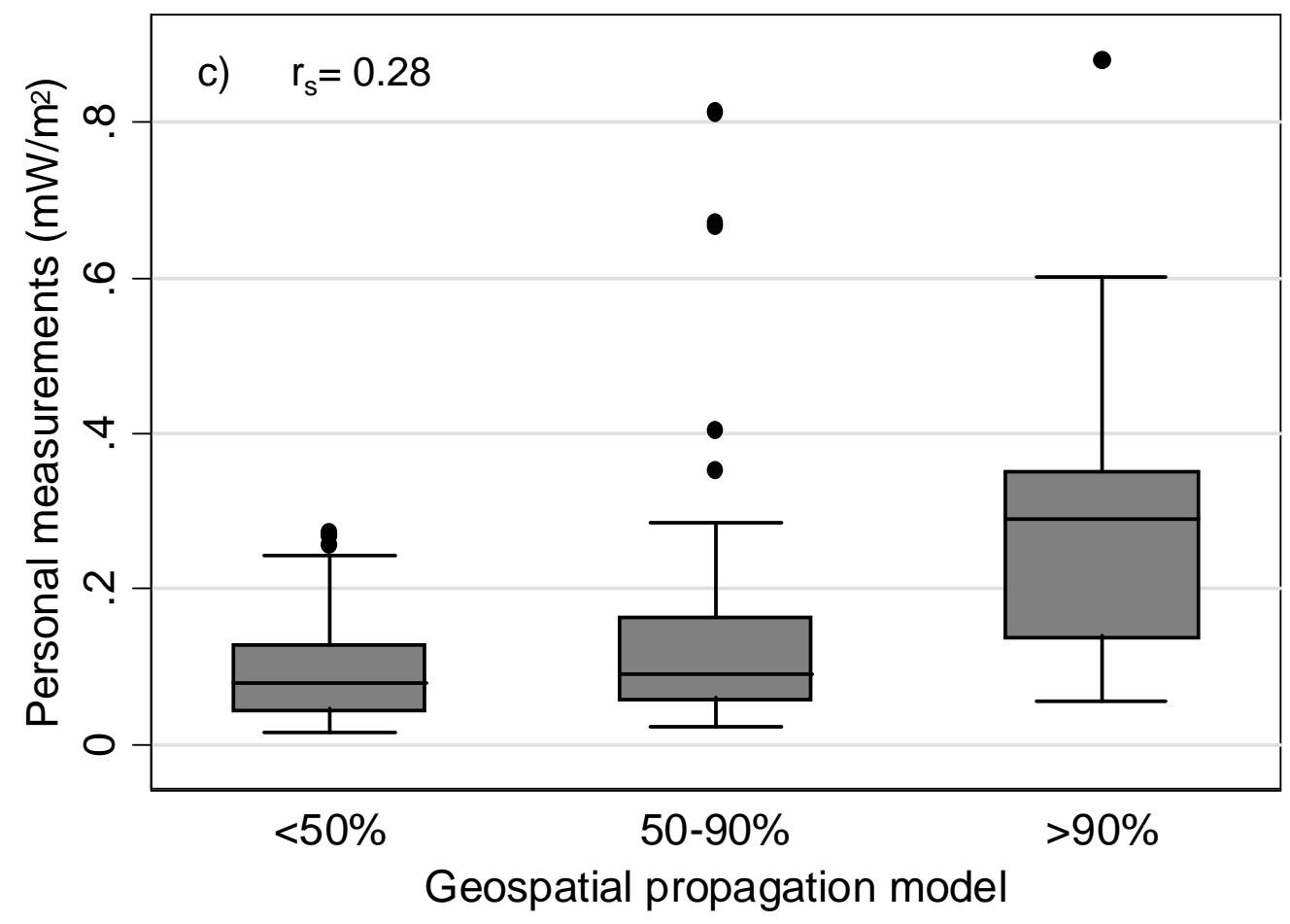




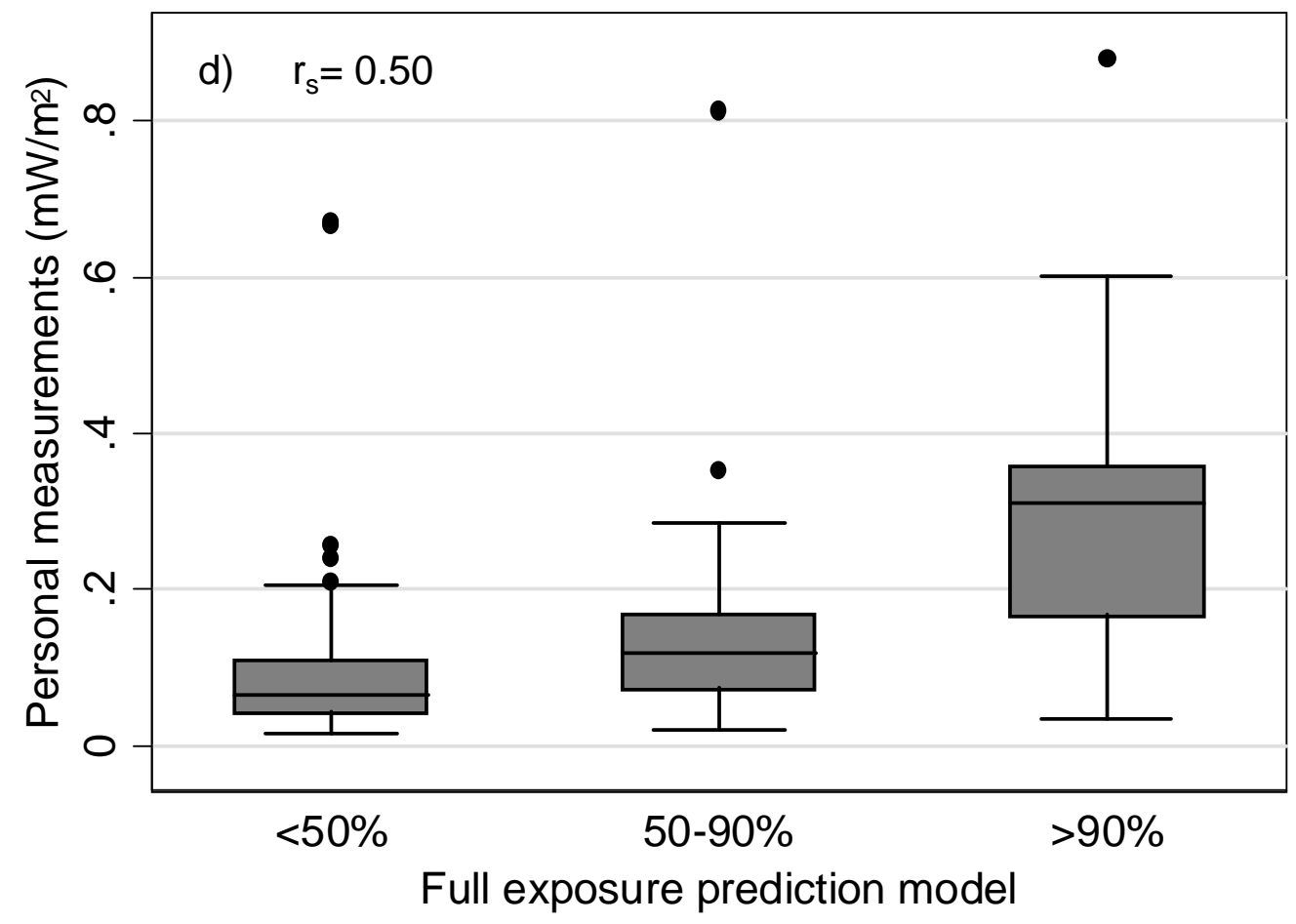




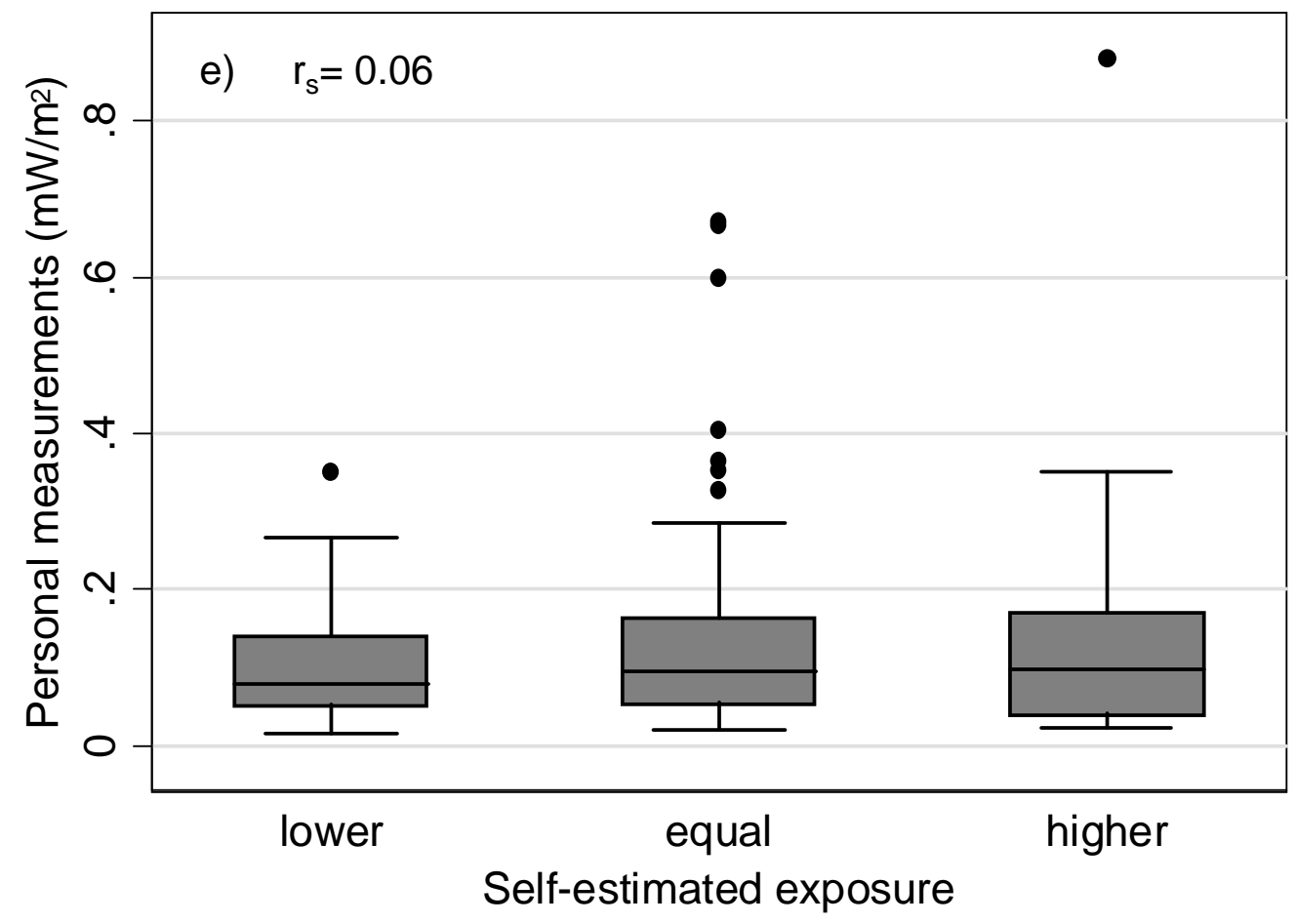

